\title{
EXPLORAÇÃO DA UTILIDADE DAS BANDAS FRACTAIS NA CLASSIFICAÇÃO DE IMAGENS DIGITAIS
}

\author{
MARCOS HIRÃARRUDAMARTINS*
}

\author{
DISSERTAÇÃO DE MESTRADO - Programa de Pós-Graduação - UFRGS \\ DATA DE DEFESA: 24 out. 2001
}

Presentemente, cresce o interesse com respeito à utilização de atributos espaciais no processo de classificação automática de imagens digitais. Este crescimento pode ser percebido pela quantidade cada vez maior de trabalhos científicos publicados sobre o assunto. Nesta dissertação, o interesse recai sobre o uso de atributo espacial. É explorado o uso da dimensão fractal para caracterizar e separar classes de textura em imagens digitais de sensoriamento remoto. A dimensão fractal pode ser considerada como um indicador da complexidade espacial das imagens de sensoriamento remoto e, neste trabalho, é calculada por dois métodos: método dos Prismas e método Direcional. Os dados são organizados em um formato similar ao utilizado para bandas espectrais, apresentando-se, portanto, como bandas de dimensão fractal, transformadas para valores de contador digital (entre 0 e 255). A distância de Bhattacharya é utilizada para estimar a separabilidade entre pares de classes e o algoritmo da máxima verossimilhança gaussiana é utilizado para classificar os pixels em imagens formadas por bandas fractais, banda original e bandas fractais junto com uma banda de dados originais. A maior diferenciação entre classes, junto com os elevados percentuais de acerto em amostras de teste, indicam que a abordagem fractal pode ser útil nos processos de classificação automática. Além disso, os experimentos de classificação realizados mostraram evidências de que os dois métodos para cálculo da dimensão fractal são diferentes quanto à exatidão de classificação.

\footnotetext{
*E-mail:mhir@cpovo.net
} 